\title{
Improving the West Greenland Trawl Survey for Shrimp (Pandalus borealis)
}

\author{
D. Carlsson and P. Kanneworff \\ Pinngortitaleriffik-Greenland Institute of Natural Resources \\ Pilestræde 52, P. O. Box 2151, DK-1016 Copenhagen K, Denmark \\ O. Folmer ${ }^{1}$ and M. Kingsley \\ Pinngortitaleriffik-Greenland Institute of Natural Resources \\ P. O. Box 570, DK-3900 Nuuk, Greenland \\ M. Pennington \\ Institute of Marine Research \\ P. O. Box 1870 Nordnes, N-5817 Bergen, Norway
}

\begin{abstract}
A stratified random research trawl survey has provided estimates of biomass and biological parameters for the West Greenland stock of northern shrimp, Pandalus borealis since 1988. About 200 stations distributed over the fishing grounds at depths between $150 \mathrm{~m}$ and $600 \mathrm{~m}$ were allocated in proportion to stratum area. The survey was extended into southern fishing grounds as the fishery developed there. Gear changes included replacing a $44 \mathrm{~mm}$ stretch mesh liner with $20 \mathrm{~mm}$ since 1993, and using a trawleye to time the tow start since 1997. Total biomass estimates have had coefficients of variance in the range of $13-23 \%$, and have been only weakly correlated with catchesper-unit effort. The survey design was reviewed in 1997, and the changes suggested included abandoning 2-stage sampling, shortening the tows and increasing their number, allocating more stations to the strata with high yields and variances, and fixing the position of some stations. Suggested changes to the analysis included pooling strata into larger depth-based groups, logtransforming the data to reduce its skewness, and smoothing the survey results. To implement some of these suggestions, a progressive shift toward shorter tows was initiated, and some halfhour tows were experimentally carried out as pairs of 15-min tows. Using shorter tows did not appear to compromise the precision of biomass estimates. The proportion of stations allocated to strata within which catches were highly variable from place to place was increased. Buffered sampling was used to control station placement so as to prevent stations from clustering within strata. Fixing the positions of a random selection from among the trawl stations from one year to the next resulted in more precise biomass estimates.
\end{abstract}

Keywords: shrimp, stratified-random survey, survey methodology, trawl survey, West Greenland

\section{Introduction}

Surveys are an indispensable adjunct to commercial catch and effort data for the assessment of marine resources because they provide wider coverage of the stock than the fisheries, which concentrate on the most lucrative grounds. Since 1988, the West Greenland shrimp stock has been monitored with a dedicated trawl survey designed to produce quantitative estimates of biomass and size composition. The survey results (1988-98) have been variable
(CV of 17\%), randomly erratic (serial correlation of 0.12 ), and not well correlated with the CPUE series (correlation coefficient 0.26) (Fig. 1). In 1997 the design and performance of the survey were reviewed and some changes recommended. This article reviews characteristics of the survey's design and performance, the rationale for the suggested changes, and progress toward their implementation. It should be noted that at the time of the Pandalid Shrimp Symposium (September 1999) only some changes had been implemented, consequently, it was not possible to

${ }^{1}$ Present address: Danish Fisheries Research Institute, Charlottenlund Slot, DK-2920 Charlottenlund, Denmark 


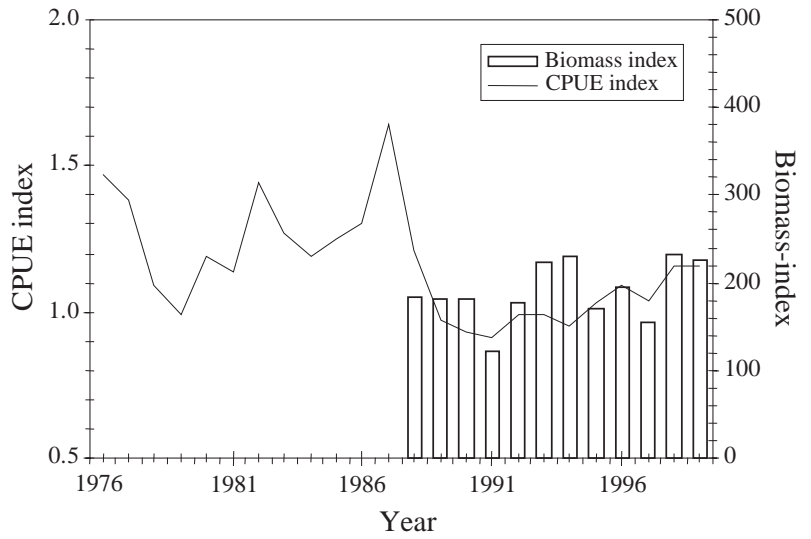

Fig. 1. Standardized CPUE (catch-per-unit-effort) index for the shrimp fishery at West Greenland 1976-99 and biomass index estimates from the offshore stratifiedrandom trawl surveys 1988-99.

present an exhaustive analysis. However, additional results have since become available and these are briefly described in the concluding section.

With recent annual catches of around 60000 tons, the fishery for northern shrimp, Pandalus borealis is a major part of the Greenland economy. Off West Greenland the stock is fished commercially at intermediate depths in cross-shelf gullies leading toward the entrances of major coastal fjord systems, and in a narrow band along the outer edge of the shelf. The fishery is therefore localised and patchy (Fig. 2).

Catch and effort data from the fishery, or at least from some fleet components, are available since 1976 (Hvingel et al., 2000). Two periods can be distinguished. From 1976 through 1989 catches per unit of effort (CPUEs) were relatively high with a mean of $82 \%$ of the 1976 value, the coefficient of variation was high (CV of $16 \%$ ) and the first-order serial correlation was low (25\%), indicating erratic variation. From 1989 through 1998, the average CPUE has been lower at $68 \%$ of the 1976 value $(83 \%$ of the 1976-89 mean), but also less variable (CV of $8.5 \%$ ) and less erratic, with an increasing trend (Fig. 1) and serial correlation of $69 \%$.

\section{Survey design}

The survey was designed as a stratified random survey (Cochran, 1977; Carlsson and Kanneworff, MS 1998a). While a principal objective was to estimate the commercially fishable biomass of northern shrimp, an important secondary objective was to estimate numbers and biomass of age- (size-) classes not yet recruited to the fishery.
Based on the distribution of the species and the fishery, the population sampled was the offshore West Greenland stock of Pandalus borealis in depths between 150 and $600 \mathrm{~m}$. Initially only the offshore fishing areas were covered, but the inshore areas of Disko Bay and Vaigat, which long had productive and stable shrimp fisheries, were added to the survey in 1991. Strata corresponded to major latitudinal divisions of the West Greenland fishing grounds (Fig. $3)$. Where depth data were available, strata were subdivided by depth (150-200 m; 201-300; 301-400; 401-600), a common practice in fishery survey design and appropriate for the depth preference of this species and its fishery. Stations were allocated to sub-strata in proportion to area, with a minimum of 2 stations per stratum, to allow standard errors to be estimated for all strata. Stations were randomly placed within strata.

The annual surveys have typically lasted from about 15 July to about 20 September, and included about 150-200 stations directed toward northern shrimp. Because shrimp move off the bottom at night, trawl stations were fished only during daylight hours, between approximately $0500-0600$ and $1600-1700$ local sun time, depending on longitude, which has a 15-degree range over the survey area.

The standard tow duration in the survey was 1 hour. The fishing gear has had few modifications over the history of the survey. The main changes were a reduction in the size of the cod-end liner mesh (from $44 \mathrm{~mm}$ to $20 \mathrm{~mm}$ in 1993), and the adoption of a trawleye to determine the start of effective fishing (in 1997). Size composition and other stock parameters are estimated from a sample of the catch taken from the cod-end at each station.

\section{Survey performance}

The estimated error coefficient of variation (ECV) of the shrimp biomass estimate has varied from about $13 \%$ to $23 \%$ (Table 1 ). The coefficient of variation (CV) of the series of estimates is about $18 \%$. As the latter variation is expected to equal the sum of the estimation uncertainty and the variation in true biomass, this implies that most of the variation in the series of biomass estimates has been due to survey sampling error, and little of it due to real variation in stock biomass.

\section{Past modifications}

The distribution of the fishery has changed during the survey series. Fishing grounds off southern West Greenland have become increasingly exploited, while some northern areas appear to have been largely 


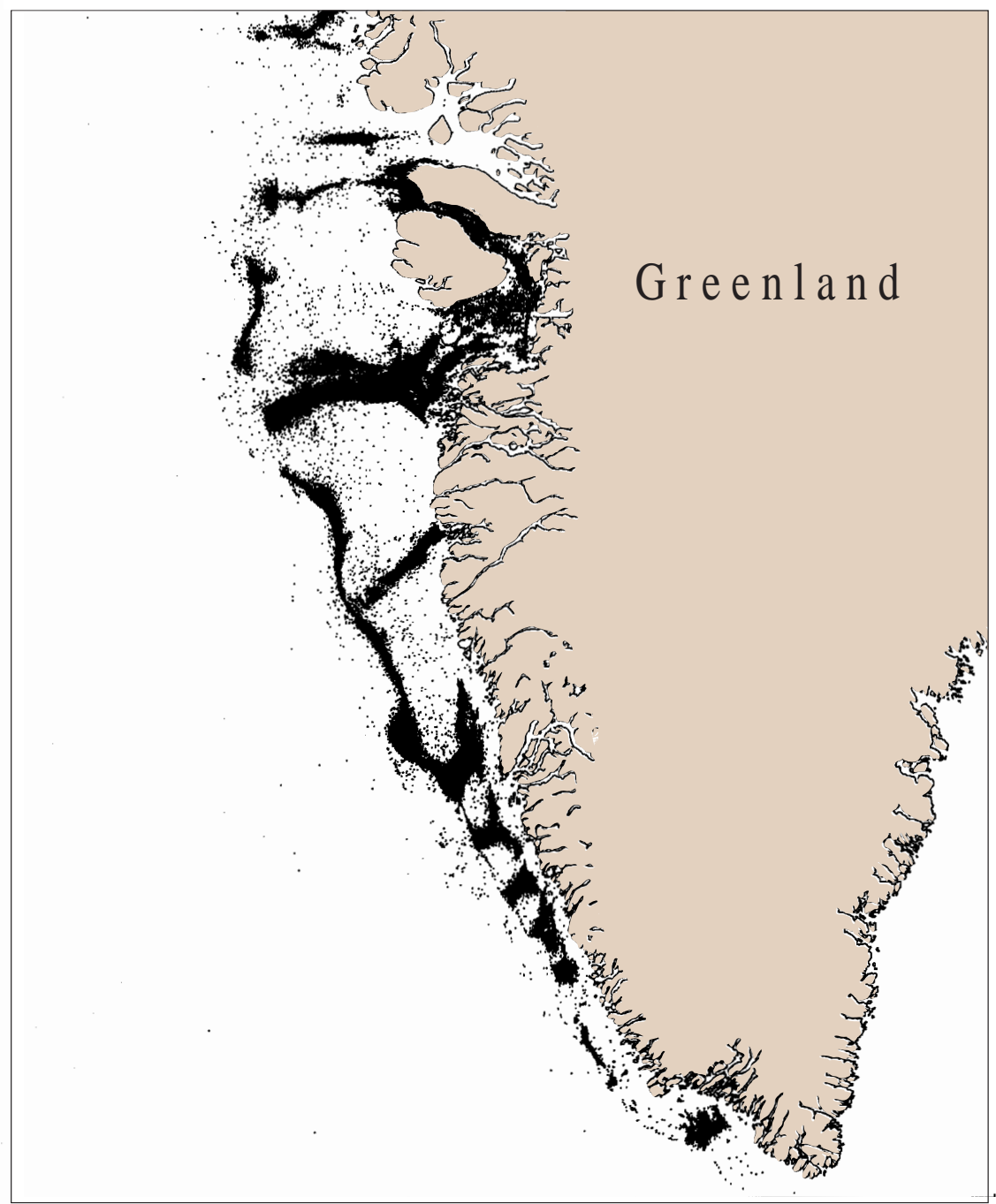

Fig. 2. Distribution of the shrimp fishery in West Greenland waters, from logbook positions 1991-98.

abandoned (Hvingel and Folmer, MS 1998). The design of the survey and the allocation of survey stations were changed accordingly, with the survey area and effort increasingly extended south of $62^{\circ} \mathrm{N}$. The change in the distribution of the fishery was assumed to reflect a change in distribution of the shrimp stock itself. If this assumption was incorrect, biomass estimates made in different periods might not be comparable.

From 1994 through 1997 a 2-stage survey procedure was applied to reduce the estimated ECV (Francis, 1984). Extra stations were allocated to strata where preliminary data analysis at sea had shown high variance in catches.

\section{Recent review and suggested modifications}

In 1997, the West Greenland shrimp survey was reviewed (Carlsson et al., MS 1998), and modifications were proposed with a view to lowering the estimated ECV and variance of survey results. The main modifications suggested were:

- abandon dynamic allocation of stations;

- use buffered sampling;

- allocate more stations to high-catch strata;

- fix stations;

- shorten tows;

- pool strata;

- transform the data;

- smooth the resulting biomass estimates; 


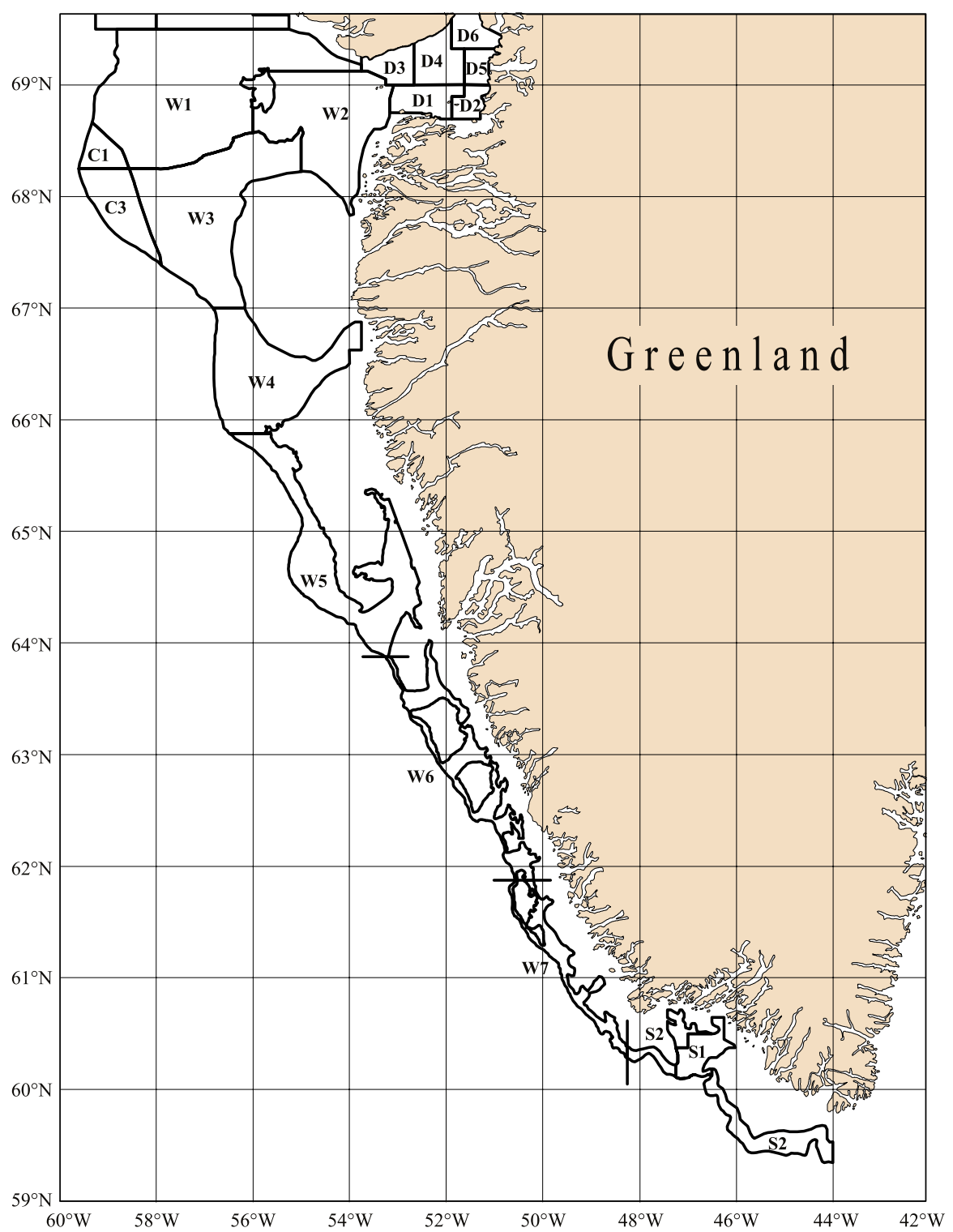

Fig. 3. Stratification scheme of the West Greenland trawl survey for northern shrimp, south of $69^{\circ} 30^{\prime} \mathrm{N}$.

\section{Abandon dynamic allocation of stations}

The statistical properties of 2-stage sampling appear to be undesirable. In resource surveys, variance and mean are positively correlated (Taylor, 1961). Therefore, adding stations to strata with a high firstsample variance tends to add stations to strata where the first sample yielded high catches. If these high catches are the result of sampling variation, and some inevitably are, the added stations produce lower results and the existing unbiased result is replaced by a downward-biased result (Francis, 1991; Jolly and Hampton, 1991).

Second-stage stations in the West Greenland survey had lower mean catches than first-stage stations in the same strata. For 115 first- and 89 secondstage samples taken from 36 strata over 4 years, the total biomass estimate from second-stage stations was $61 \%$ (SE 9.3\%) of that from the firststage samples (Fig. 4). Second-stage samples tended to be taken in strata where the first samples 
TABLE 1. Biomass estimates and error coefficient of variation (ECV) of the West Greenland series of trawl surveys for northern shrimp Pandalus borealis.

\begin{tabular}{|c|c|c|c|c|c|c|}
\hline & \multicolumn{2}{|c|}{ Offshore } & \multicolumn{2}{|c|}{ Disko Bay } & \multicolumn{2}{|l|}{ Total } \\
\hline & $\begin{array}{l}\text { Biomass estimate } \\
\text { ('000 tons) }\end{array}$ & ECV (\%) & $\begin{array}{l}\text { Biomass estimate } \\
\text { ('000 tons) }\end{array}$ & ECV (\%) & $\begin{array}{c}\text { Biomass estimate } \\
\text { ('000 tons) }\end{array}$ & $\operatorname{ECV}(\%)$ \\
\hline 1988 & 183.3 & 14 & & & 183.3 & 14 \\
\hline 1989 & 181.5 & 15 & & & 181.5 & 15 \\
\hline 1990 & 181.8 & 18 & & & 181.8 & 18 \\
\hline 1991 & 122.0 & 16 & 50.6 & 23 & 172.6 & 13 \\
\hline 1992 & 177.8 & 17 & 47.4 & 16 & 225.1 & 14 \\
\hline 1993 & 223.2 & 13 & 33.6 & 21 & 256.8 & 12 \\
\hline 1994 & 230.6 & 22 & 40.0 & 26 & 270.6 & 19 \\
\hline 1995 & 169.8 & 17 & 47.3 & 17 & 217.1 & 14 \\
\hline 1996 & 194.6 & 21 & 54.3 & 10 & 248.9 & 16 \\
\hline 1997 & 153.9 & 19 & 52.3 & 14 & 206.2 & 15 \\
\hline 1998 & 231.4 & 23 & 61.9 & 18 & 293.3 & 19 \\
\hline 1999 & 226.2 & 18 & 61.2 & 14 & 287.4 & 14 \\
\hline CV (\%) & 17.7 & & 18.4 & & 19.2 & \\
\hline Skewness $(\%)$ & -39.6 & & -40.3 & & 24.8 & \\
\hline Serial Correlation (\%) & 11.9 & & 65.0 & & $12.5^{1}$ & \\
\hline
\end{tabular}

${ }^{1}$ Calculated for the series only from 1991 in surveys that included Disko Bay.

had averaged above the true stratum mean and therefore induced a negative bias.

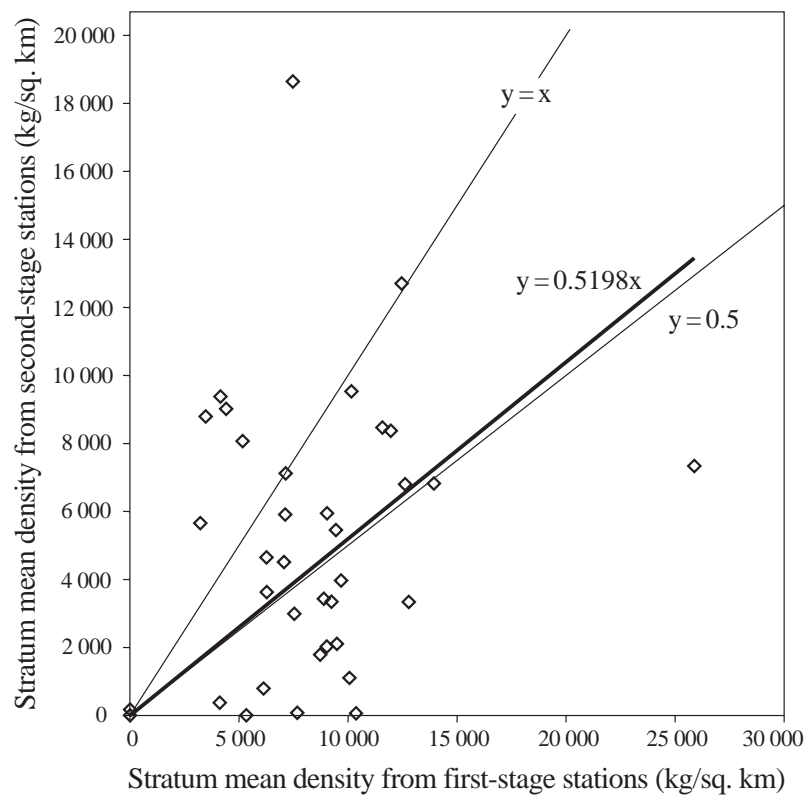

Fig. 4. Stratum mean densities from 115 first-stage and 89 second-stage trawl samples in 36 strata sampled by 2-stage sampling in the West Greenland shrimp survey between 1994 and 1997.
Dynamic allocation of stations also incurs logistic inefficiencies of extra steaming and back-tracking to add stations in areas already sampled. For these reasons, dynamic allocation of stations during the course of the survey has been abandoned, in favour of executing a predetermined design.

\section{Use buffered sampling}

Simple random sampling is an accepted method of placing survey stations (Doubleday, 1981), and yields unbiased estimates with known error variance (Cochran, 1977). It is also easy to do. However, it often produces an apparently uneven distribution of stations, which does not help in securing acceptance of survey results among user communities. Simple random sampling is also inefficient when populations are spatially auto-correlated so stations close together duplicate each other's results.

Systematic sampling is efficient for sampling auto-correlated populations (Cochran, 1977) and is well suited to large areas with large, regular-shaped strata and uniform sampling densities. However, it is difficult to apply in stratified surveys where strata are irregular, where sampling density varies from stratum to stratum, and where a set number of stations are to be placed in each stratum. All these are characteristics of the West Greenland shrimp survey. 
Buffered sampling adapts well to stratified surveys with sampling densities that vary from stratum to stratum. It can be applied to irregularly shaped strata. In this sampling method, a fixed number of stations are placed randomly within a stratum. However, no two stations can be closer together than a prescribed limiting distance. If the limiting distance is small, the design approaches a simple random sample. If it is large, the design approximates a systematic sample.

This sampling procedure is unbiased. Its error properties are between those of random and systematic sampling. In spatially auto-correlated populations it is more efficient than simple random sampling but no unbiased estimate of error variance exists except in random populations.

\section{Allocate more stations to high-catch strata}

A single objective of minimising the error variance of the estimate of fishable biomass would not imply allocating stations proportional to stratum area. Instead, stations would be allocated proportionally to the expected error variance of the stratum estimate of fishable biomass, most probably based on survey catches in recent years. Survey efficiency can also be improved if fishery records are referred to in allocating stations to strata (Smith and Gavaris, 1993; Gavaris and Smith, 1987). An algorithm was developed for allocating stations to strata, proportionally to an exponentially weighted mean of past years' error variances of the stratum biomass estimate. However, the West Greenland shrimp survey also has additional objectives, such as estimating numbers of small shrimp not yet recruited to the fishery. These small shrimp mainly occur in shallower water in low-catch strata. The effect on other objectives of allocating stations optimally for estimation of total biomass is not yet known.

\section{Fix stations}

Stratified random surveys for fishery resources are usually designed by replacing the positions of sampling stations for each (annual) survey. This procedure yields estimation errors that are serially uncorrelated between years, and maximises random between-year variation, ensuring that changes in the biomass estimate due only to changes in stock distribution remain within the sampling variation and are not mistakenly ascribed to changes in stock size. If stock distribution is stable, fixing station positions from year to year allows more sensitive between-year comparisons, as catches can be compared station by station. Fishery surveys that use systematic designs are less affected by changes in stock distribution than randomly sampled surveys, and often use fixed stations. Buffered sampling, which approximates systematic sampling, is also compatible with the use of fixed stations.

Fixing station positions from year to year has logistic advantages. For example, good bottom conditions for trawling may be found more quickly by referring to past experience. However, fixing all stations fixes the entire survey design. Therefore, a compromise was implemented by fixing a randomly chosen $50 \%$ of stations from year to year and replacing the remainder. This will allow an assessment of the performance of a fixed-station design relative to that of re-sampling in estimating year-to-year changes in stock biomass. It also retains flexibility in reallocating stations from one stratum to another.

\section{Shorten tows}

Existing information (e.g. Pennington and Vølstad, 1991; Gunderson, 1993) appears to indicate that fishery resources have high short-range spatial correlation in biomass density (and other properties, such as mean size of organisms). A corollary is that small samples at a station may be as informative as large ones: high spatial correlation means that the second half of a large sample adds little information. This implies that tows shorter than the present standard of one hour might be more efficient for the West Greenland survey.

The optimum sample size depends on the fixed time per station and on the spatial structure of the resource. If the resource shows a strong spatial correlation, short tows are efficient, but fixed costs reduce their advantages. Steaming time per station is semi-fixed: it decreases if stations are closer together. Average steaming time per station in this survey was about 56 minutes and a fixed time of about 45 minutes: about 20 minutes search time and 25 minutes gear handling. Ignoring complications such as steaming between stations at night and the different spacing of stations in different strata, it appeared that if tows lasted 30 minutes instead of 60 , closer spacing could reduce average steaming time to about 50 minutes and about $30 \%$ more stations could be sampled. If tows were to be shortened to $15 \mathrm{~min}, 44 \%$ more stations could be sampled and ECVs reduced by perhaps $17 \%$, assuming that the ECV is inversely proportional to the square root of the sample size and that catch variation between tows remains the same.

Sampling more stations would not proportionally increase survey precision if shorter tows were more 
variable. Spatial correlation of shrimp density was examined in the 1997 survey by experimentally carrying out 7 contiguous 60 -minute tows along each of three isobathic transects. No spatial correlation could be detected, but the CV along these isobathic transects was only $30-40 \%$, while the within-stratum $\mathrm{CV}$ in the survey is usually about $100 \%$ (Kingsley and Carlsson MS 1998). That is, the spatial correlation may have been low because the isobathic transects were too short to encounter great variations in density. It was difficult to predict the effect of shorter tows on survey precision from this experiment.

In the 1998 survey, about 50 of the standard 60minute tows were experimentally replaced with 30 minute tows. In $1999,50 \%$ of the tows lasted 60 minutes, $25 \% 30$ minutes, and $25 \% 15$ minutes. Density estimates from short tows were as precise as from long ones (Carlsson and Kanneworff, unpublished data; Kingsley et al., MS 1999; Folmer and Pennington, 2000).

Increasing the number of stations should also improve estimates of the biological parameters of the resource. If size composition of fishery resources is spatially correlated more strongly than density, i.e. patches tend to consist of animals of similar size although the density within the patch may be variable, the gain in precision from more stations is only offset by a small penalty due to smaller samples (Pennington and Vølstad, 1994).

\section{Pool strata}

Primary stratification by geographical area is a basis for allocation of stations and ensures that they are well distributed over the study area. However, within areas $\mathrm{W}$ and $\mathrm{C}$, there is little variation in biomass density with latitude; shrimp density is depthdependent, and secondary stratification by depth (see above) is biologically and statistically more significant (Folmer and Pennington, 2000). Within areas W and $\mathrm{C}$ it is possible to pool the data for each of the defined depth bands forming four large data sets from the present 33 small ones. Expected statistical advantages would be to increase the number of degrees of freedom for calculating confidence intervals, reducing the effect of rare large catches in strata containing few stations, and facilitating the use of more sophisticated statistical analyses (Folmer and Pennington, 2000). If applied also to station allocation, larger strata could reduce the number of stations that are presently allocated to poor areas for the sole purpose of ensuring a minimum of two stations per stratum.

\section{Transform the data}

Highly skewed data may be analysed by treating it as a mixed distribution, and log-transforming the values that exceed a given limit (Pennington, 1996; Folmer and Pennington, 2000). If the distribution of the large values in the population approximates the log-normal distribution, this transformation can give better estimates of population parameters. One of its effects is to reduce the influence of rare large catches on estimates of stock biomass. The performance of the transform depends on an appropriate choice of a limit between the values to be transformed and those to be used untransformed.

When this method was applied to the West Greenland shrimp survey data for strata W1-W5, C1, and $\mathrm{C} 3$, it produced larger biomass estimates when the limit value was small, and vice versa. The limit value was set to $5 \%$ of the stratum mean density by Folmer and Pennington (2000). With this limit value, the mean relative bias of estimates using the transform was about 3\% upwards over an 11-year series comprising 1082 stations (Folmer and Pennington, 2000, Table 2). Estimated standard errors were on average increased by about $14 \%$.

Using a log-transform is expected to produce estimates that are negatively skewed, or less positively skewed, relative to the conventional estimates. When it was applied to the shrimp survey data the skewness of the distribution of conventional estimates, which was $-12 \%$, became more negative with a value of $-39 \%$ (Table 2). The relationship between the density estimate and its estimated standard error became tighter with a correlation coefficient of $81 \%$ instead of $61 \%$. It also became steeper, with a slope of 0.96 compared with 0.88 (Table 2).

\section{Smooth the results}

A more precise estimate of the stock biomass in the current year may be generated by incorporating previous years' results through smoothing than by relying on a single survey (Carlsson et al., MS 1998; Folmer and Pennington, 2000). The improvement depends on the relative magnitude of the random yearto-year variation in true stock size and the random error in estimation. If estimation error is high, but the stock size does not vary much, the gain in precision may be considerable. Analyses indicate that the variance in stock biomass over the survey series to date has been of the order of $10 \%$ of the survey error variance. If this ratio remained the same, smoothing of the survey data should produce better estimates of 
TABLE 2. Statistical properties of a log-transformation applied to West Greenland shrimp survey data for areas $\mathrm{W}$ and $\mathrm{C}$ in 1988-98 (data from Folmer and Pennington, 2000, Table 2).

\begin{tabular}{|c|c|c|}
\hline & Conventional estimates & Estimates using log-transform \\
\hline Series mean estimate $(B)(\mathrm{kg} / \mathrm{sq} \mathrm{km})$ & 2344 & 2408 \\
\hline Series standard deviation $(\mathrm{kg} / \mathrm{sq} \mathrm{km})$ & 546.5 & 556.4 \\
\hline Coefficient of Variation $(\%)$ & 23.3 & 23.1 \\
\hline Series skewness $(\%)$ & -12.1 & -39.2 \\
\hline Geometric mean of ratios of biomass estimates $\left(B_{l o g} / B_{c o n v}\right)$ & - & 1.027 \\
\hline Geometric mean of ratios of estimated SEs ${ }^{1}$ & - & 1.141 \\
\hline Log-log regression of $\mathrm{SE}^{1}$ on biomass estimate $(B)$ & $0.523 \times B^{\wedge} 0.8775$ & $0.315 \times B^{\wedge} 0.9569$ \\
\hline Correlation between $\log \mathrm{SE}^{1}$ and $\log$ biomass estimate & $0.615(\mathrm{SE} 0.220)$ & $0.815(\mathrm{SE} 0.119)$ \\
\hline
\end{tabular}

1 the estimated standard error respective to each biomass estimate

the stock biomass, which would however not be independent nor have independent errors. An application of a smoothing algorithm to the survey series is shown in Folmer and Pennington (2000).

\section{Implementation and effects of modifications}

Modifications are of two kinds: changes to the survey design and execution, and changes to the analysis. Survey design and execution tends to be 'either-or', for example, a stratum is sampled in one way or another, a tow lasts one length of time or another, a station is allocated in one stratum or another. In contrast, the same data can be analysed in more than one way and the results compared, so modifications to analysis methods are less irrevocable (although there are obvious dangers in circulating the results of different analyses without clearly qualifying their validity).

Several of the modifications listed above have been implemented. In the 1998 survey, a) two-stage sampling was abandoned, b) some stations were reallocated from strata with sparse catches into strata with higher catches, and c) some one-hour tows were replaced by half-hour tows. In 1999, further alterations to the design included, a) placing stations by buffered sampling, b) using 15-minute, 30-minute and 60minute tows randomly mixed, and c) fixing, i.e. retaining the positions of, a random selection from among the 1998 stations for re-use in the 1999 survey. Preliminary results are as follows:

- the number of stations increased from 167 in 1997 to 211 in 1998 and to 230 in 1999.

- tows as short as 15 minutes yielded density estimates as precise as those obtained from 60minute tows (Kingsley et al., MS 1999).
- from the mixing of tow durations within strata, the average trawling end error was estimated at 2.78 minutes, that is catch appeared to be approximately proportional to nominal trawl duration plus 2.78 minutes, and using shorter hauls is therefore expected to bias the survey biomass estimate upwards.

- the mean distance from a station to its nearest neighbour was increased by $50 \%$ by the use of buffered sampling (Kingsley et al., MS 1999), indicating that a more even distribution of stations was obtained (Fig. 5) while retaining the conventional expression for standard errors.

- the use of buffered sampling permitted the positions of a proportion of stations to be fixed from one year to the next.

- The catches at the stations whose positions were fixed from 1998 to 1999 were analysed as a paired sample, and also as though they were independent samples. When analysed as a paired sample, i.e. by calculating the yearto-year change in catch for each such station, the change in mean density from 1998 to 1999 was estimated twice as precisely as when they were analysed as though they were two independent stratified samples. (Kingsley et al., MS 1999).

- the estimated standard error of the overall biomass estimate changed little between 1998 and 1999.

The most significant change to the design of the survey was the start of what is likely to be a progressive shift toward shorter tows. The results available to date indicate that the standard error of the offshore survey would be reduced if more, shorter, tows were taken. In 2000, 45-minute tows will replace 60-minute tows 


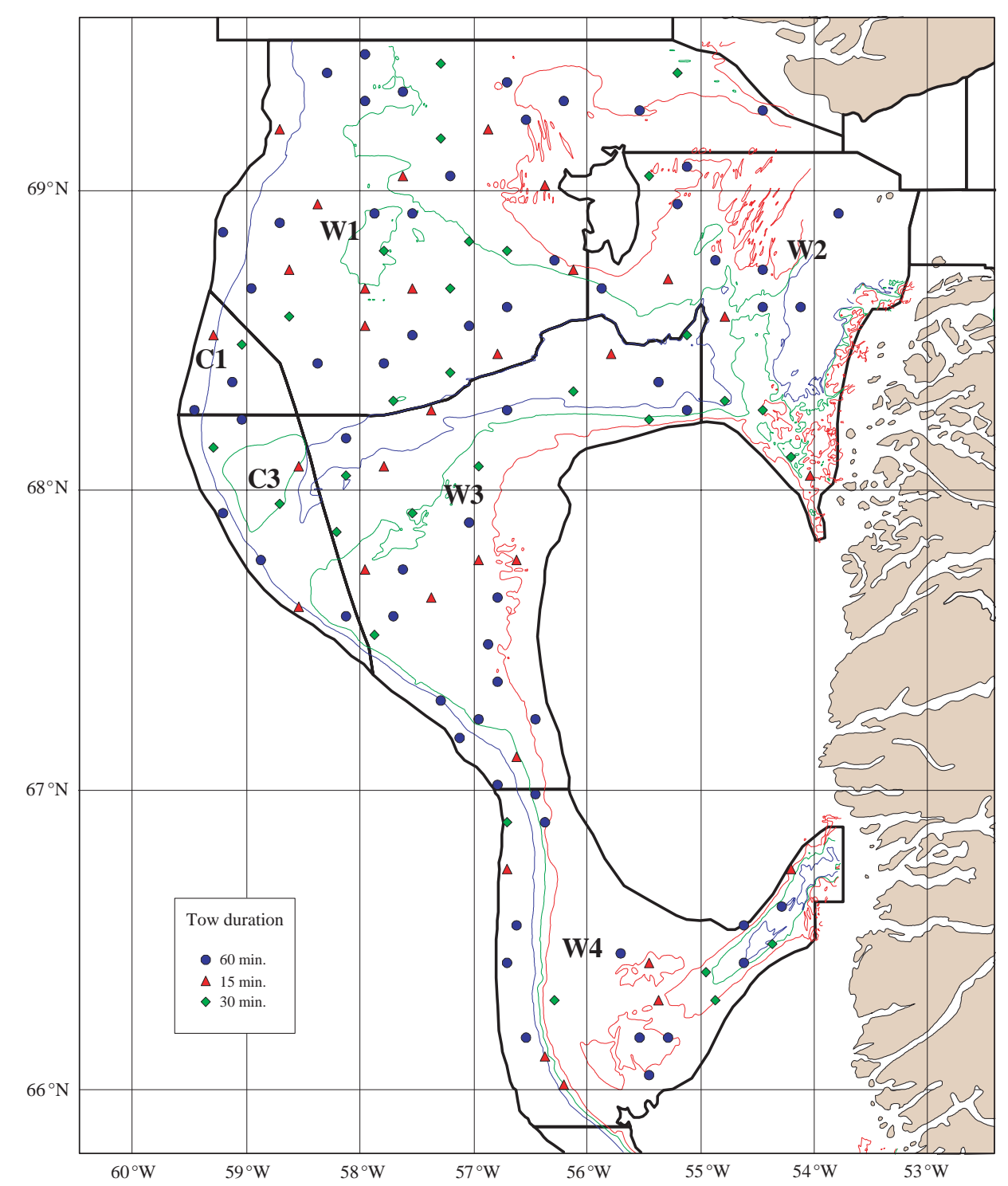

Fig. 5. Stations placed by buffered sampling in strata W1 through W4, C1, and C3 of the West Greenland shrimp survey in 1999.

and the mixture with 30-minute tows and 15-minute tows will be maintained. This will allow the results obtained from tows of different lengths to be more thoroughly compared before establishing any new standard.

The use of buffered sampling to place stations gives a more evenly distributed sample. The statistical effect of this is not large: the true standard error of estimation is slightly reduced, while the standard error estimated by the conventional formula is slightly increased. A more significant effect is that the evenly distributed sample allows fixing station positions and thereby a more precise estimation of between-year changes in biomass.
The survey review has therefore resulted in the implementation of three changes in survey design: shortening tows, placing stations by buffered sampling, and fixing stations. Shorter tows were started in 1998, and the other two changes were first implemented together in 1999. Estimating the effects of these changes should be possible and will be an interesting analytical problem.

Classical analyses can be continued while revised methods are examined and validated. In this way, the results of log-transforming the larger catches were evaluated and compared with the results obtained by standard analyses, and may therefore be regarded as partially implemented (Carlsson et al., MS 1998; 
Folmer and Pennington, 2000). Pooling stratified data into larger 'super-strata' also appears to have few drawbacks. It simplifies the analysis and presentation of results, and gives more manageable datasets (Folmer and Pennington, 2000).

\section{Acknowledgements}

We acknowledge contributions to discussions about the survey design and implementation with numerous colleagues at the Greenland Institute of Natural Resources and in other scientific fora.

\section{References}

CARLSSON, D. M., and P. KANNEWORFF. MS 1998. Offshore stratified-random trawl survey for shrimp (Pandalus borealis) in NAFO Subareas 0+1, 1998. NAFO SCR Doc., No. 118, Serial No. N4027, 18 p.

CARLSSON, D. M., O. FOLMER, C. HVINGEL, P. KANNEWORFF, M. PENNINGTON, and $\mathrm{H}$. SIEGSTAD. MS 1998. A review of the trawl survey of the shrimp stock off West Greenland. NAFO SCR Doc., No. 114, Serial N4023, 21 p.

COCHRAN W. G. 1977. Sampling techniques, 3rd edition. Wiley, New York. 428 p.

DOUBLEDAY, W. G. (ed.) 1981. Manual on groundfish surveys in the Northwest Atlantic. NAFO Sci. Coun. Studies, 2, $55 \mathrm{p}$.

FOLMER, O., and M. PENNINGTON. 2000. A statistical evaluation of the design and precision of the shrimp trawl survey off West Greenland. Fisheries Research, 49(2): 165-178.

FRANCIS, R. I. C. C. 1984. An adaptive strategy for stratified random trawl surveys. N. Z. J. Mar. Freshwater Res., 18: 59-71.

1991. Statistical properties of two-phase surveys: comment. Can. J. Fish. Aquat. Sci., 48: 1128.

GAVARIS, S., and S. J. SMITH. 1987. Effect of allocation and stratification strategies on precision of survey abundance estimates for Atlantic cod (Gadus morhua) on the eastern Scotian Shelf. J Northw. Atl. Fish. Sci., 7: $137-144$.
GUNDERSON, D. R. 1993. Surveys of fisheries resources. John Wiley and Sons, New York. 248 p.

HVINGEL, C., and O. FOLMER. MS 1998. The Greenlandic fishery for northern shrimp (Pandalus borealis) off West Greenland, 1970-1998. NAFO SCR Doc., No. 111, Serial No. N4020, 24 p.

HVINGEL, C., H. LASSEN, and D. G. PARSONS. 2000. A biomass index for northern shrimp (Pandalus borealis) in Davis Strait based on multiplicative modelling of commercial catch-per-unit-effort data (1976-97). J. Northw. Atl. Fish. Sci., 26: 25-36.

JOLLY, G. M., and I. HAMPTON. 1991. Reply to comment by R.I.C.C. Francis. Can. J. Fish. Aquat. Sci., 48: 11281129.

KINGSLEY, M. C. S., and D. M. CARLSSON. MS 1998. An experimental investigation on spatial and depth variation in catch of shrimp, Greenland halibut and redfish. NAFO SCR Doc., No. 119, Serial No. N4028, 6 p.

KINGSLEY, M. C. S., I. STIRLING, and W. CALVERT. 1985. The distribution and abundance of seals in the Canadian high Arctic, 1980-82. Can. J. Fish. Aquatic Sci., 42(6): 1189-1210.

KINGSLEY, M. C. S., P. KANNEWORFF, and D. M. CARLSSON. MS 1999. Modifications to the design of the trawl survey for Pandalus borealis in West Greenland waters: effects on bias and precision. NAFO SCR Doc., No. 105, Serial No. N4184, 15 p.

PENNINGTON, M. 1996. Estimating the mean and variance from highly skewed marine data. Fish. Bull., 94: 498-505.

PENNINGTON, M. and J. H. VØLSTAD. 1991. Optimum size of sampling unit for estimating the density of marine populations. Biometrics, 47: 717-723.

PENNINGTON, M. and J. H. VØLSTAD. 1994. Assessing the effect of intra-haul correlation and variable density of estimates of population characteristics from marine surveys. Biometrics, 50: 725-732.

SMITH, S. J., and S. GAVARIS. 1993. Improving the precision of abundance estimates of eastern Scotian Shelf Atlantic cod from bottom trawl surveys. N. Am. J. Fish. Manage., 13: $35-47$.

TAYLOR, L. R. 1961. Aggregation, variance and the mean. Nature, 189: 732-735. 